\title{
PREPARATION OF PLANT MUCILAGE CLARIFICANTS AND THEIR EFFECT ON JAGGERY PROCESSING OF SUGARCANE VARIETY Co 86032
}

\author{
LAVA CHIKKAPPAIAH ${ }^{1}$, HARISH NAYAKA M. A. ${ }^{* 1}$, MAHADEVAIAH ${ }^{1}$, PRASHANTH KUMAR G. M. ${ }^{2}$ \\ ${ }^{1}$ Department of Studies in Sugar Technology, Sir M. Visvesvaraya Post Graduate Centre, University of Mysore, Tubinakere, Mandya \\ 571402, India, ${ }^{2}$ Survey of Medicinal Plants Unit, Regional Ayurveda Research Institute for Metabolic Disorders, Jayanagar, Bangalore \\ 560011, India \\ Email: harish_nayaka4@yahoo.com \\ Received: 02 Aug 2017 Revised and Accepted: 16 Oct 2017
}

\begin{abstract}
Objective: The aim of the study was to prepare jaggery from sugarcane variety Co86032 using plants mucilage as clarificants and to determine the effect of plant mucilage on jaggery processing.

Methods: Production of jaggery using five plant clarificants namely Aloe vera, Flax seeds, Fenugreek, Purslane and Malabar spinach at three different concentrations i.e., $0.1 \%, 0.2 \%$ and $0.4 \%$ of raw sugarcane juice and the jaggery prepared without any clarificants serves as control. During production, the processing parameters such as quantity of scum removed, total time taken for processing and jaggery yield was determined.

Results: It was found that the jaggery prepared using plant mucilage at concentration of $0.4 \%$ found superior when compared to $0.2 \%, 0.1 \%$ and control respectively. Aloe vera at $0.4 \%$ removed maximum scum (4.07\%), taken minimum processing time (72.33 min) and recorded maximum jaggery yield $(10.92 \mathrm{~kg})$. The efficacy of Aloe vera as mucilage clarificants in jaggery production was followed by fenugreek, flax seeds, purslane and Malabar spinach in the order respectively.

Conclusion: The application of plants mucilage as clarificants in the jaggery production removed significant level of scum, reduced processing time and improved yield of jaggery. Therefore the selected plant mucilages can be used as clarificants in the jaggery production and can be considered as
\end{abstract} potential alternative to chemical clarificants.

Keywords: Jaggery processing, Plant mucilage clarificants, Jaggery yield, Processing time

(c) 2017 The Authors. Published by Innovare Academic Sciences Pvt Ltd. This is an open access article under the CC BY license (http://creativecommons.org/licenses/by/4.0/) DOI: http://dx.doi.org/10.22159/ijpps.2017v9i12.22377

\section{INTRODUCTION}

As a result of rapid growth in population, food and its safety remain to be the most important criteria for existence of life. Growing awareness of health hazards that may be caused by the excessive use of chemicals in modern agriculture and during food processing has made consumers to shifts towards organic foods. Jaggery is used as a sweetening agent and as a source of energy by millions of people in their daily food. Hence there is huge demand for the jaggery and jaggery products in domestic market as well as international market. Jaggery production is among major agro processing industries in India and to meet the high demand for organic jaggery, it is very much essential to produce the jaggery with high nutritive content and good storage quality.

Jaggery production involves extraction of juice, clarification and concentration. Clarification is a process of elimination of non sugar impurities in the extracted raw sugar cane juice [1]. If the non sugar impurities are not removed during clarification, they will be carried over to the next subsequent processing and eventually embedded in the jaggery resulting in the inferior quality of jaggery [2]. In an attempt to improve the business potential of jaggery, the manufactures are adding chemical clarificants at undefined rate during clarification. The chemical clarificants such as Hydros, sodium carbonate, sodium bicarbonate, super phosphate alum, sodium formaldehyde sulfoxylate, Tri sodium phosphate and magnafloc are used in the jaggery preparation [3-5]. It is also reported that at farm level manufactures are using some chemicals which are unlabelled and safety limits not set by regulatory bodies [3]. Though the chemicals clarificants improve the colour, texture and reduce crystallization temporarily but they eventually hastens colour darkening and process of spoilage within a month thereby adversely affects the keeping quality and may not be fit for storage as well as for consumption [5-7]. The recommended limit of Hyros (Sodium Hydro sulphite) is 35g per 1000 litres of sugarcane juice but at this concentration it is very difficult to achieve the desirable light golden colour jaggery. Hence to achieve the desirable colour the manufactures are adding excess hydrous which exceeds $50 \mathrm{ppm}$ of sulphur dioxide which is not suitable for human consumption [8] and therefore there is a need to replace the chemical clarificant with natural source of clarificants and also minimal usage of chemical processing helps in retaining more minerals salts and phyto chemicals [9].

Mucilage is a polysaccharide complex [10] present in plants found to have variety of biological activities [10]. It is widely explored in the field of pharmaceuticals, therapeutics, food and cosmetics (11-14). Plant mucilage is natural, renewable, locally available and less expensive when compared to synthetic clarificants. Many plants clarificants have been already reported, namely Deola (Hibiscus ficulneus), Bhendi (Hibiscus esculentus), Castor (Recinus communis), Groundnut (Arachis hypogea), Soybean (Glycine max), Phalsa (Grewia asiatica), and Sukhalai (Kydia calycina) which were found to improve the quality of jaggery [4-6, 1518]. But still we couldn't conquer the potential market for organic jaggery. Therefore there is scope to screen novel clarificants from plants sources which could ideally replace synthetic clarificants. In this regards, the mucilage from five selected plants source namely Aloe vera, Flax seeds, Fenugreek seeds, Purslane and Malabar spinach was used as clarificants in the preparation of jaggery due to presence of significant level of mucilage in the selected plants, locally availability and simple process of extraction of mucilage. It was found through literature survey that there are no reported studies on application of the selected plant mucilage in the clarification of sugarcane juice. Therefore the study was aimed at preparing the jaggery using the selected plants mucilage as clarificants and to determine their effect on jaggery processing parameters such as quantity of scum removed, total time taken for processing and jaggery yield.

\section{MATERIALS AND METHODS}

\section{Samples}

For this study the sugarcane variety Co 86032 was selected which has been extensively cultivated in the Mandya and Mysore Dist, Karnataka 
state India. The sugarcane sample was of 10 mo age collected from Zonal Agricultural Research Station, V. C. Farm, Mandya, Karnataka. The plants such as Malabar Spinach, Purslane and Aloe vera were collected from field and Flax seeds and Fenugreek seeds were collected from Shop, Mysore. The plants materials were taxonomically identified and authenticated by Dr. Shiddamallayya at Regional Ayurveda Research Institute for Metabolic Disorder, Bangalore, where the voucher specimen is conserved under the reference numbers: Aloe vera (RRCBI-16202), Flax seeds (RRCBI-11993), Fenugreek (RRCBI-14595), Malabar spinach (RRCBI-13822) and Purslane (RRCBI-14595).

Table 1: Plant mucilage clarificants used for jaggery production

\begin{tabular}{llll}
\hline Common name & Botanical name & Parts to be used & Reference method for mucilage extraction \\
\hline Aloe vera & Aloe vera (L.) Burm. f. & Leaf & {$[19]$} \\
Flax seeds & Linum usitatissimum L. & Seeds & {$[20]$} \\
Fenugreek & Trigonella foenum-graecum L. & Seeds & {$[20]$} \\
Purslane & Portulaca oleracea L. & Leaf and stem & {$[21]$} \\
Malabar spinach & Basella alba L. & Leaf and stem & {$[22]$} \\
\hline
\end{tabular}

\section{Extraction and confirmative test of mucilage}

The reference methods for mucilage extraction were modified and standardise based on laboratory trails and suitability. The standardised method for extraction of mucilage from plants sources was expalined in table 2 . The extracted mucilage was subjected to chemical tests such as molisch test and ruthenium red test to confirm its identity [23].

\section{Molisch test}

Take $0.5 \mathrm{~g}$ of mucilage dissolved in $5 \mathrm{ml}$ of distilled water in test tube and treat with few drops of $1 \%$ alcoholic alpha napthal. Add $2 \mathrm{ml}$ of concentrated sulphuric acid along the sides of the test tube. The presence of carbohydrates was indicated by the formulation of purple ring between two layers.

\section{Ruthenium red test}

A small quantity of extract was suspended with water and added ruthenium red solution. Formation of pink colour showed the presences of gums and mucilage's.

\section{Preparation of mucilage}

Clarificants were prepared with 3 different concentrations, namely $0.1 \%, 0.2 \%$ and $0.4 \%$ of the quantity of raw sugar cane juice taken for clarification (table 3 )

Table 2: Steps involved in extraction of mucilage from plant sources

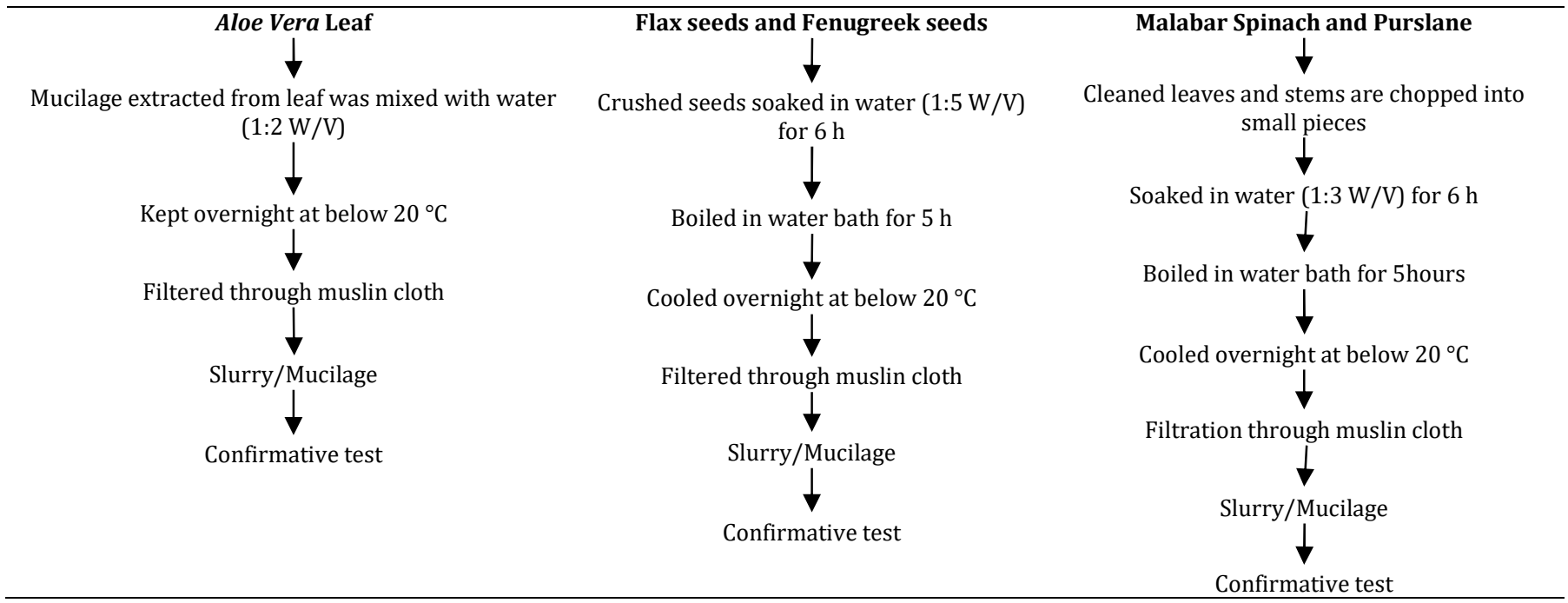

Table 3: Preparation of mucilage clarificants for 10L Sugarcane raw Juice

\begin{tabular}{|c|c|c|c|}
\hline Experiment & Sample code & Mucilage concentration & Quantity(g) of mucilage per $10 \mathrm{~L}$ of juice \\
\hline Control & JNC & No mucilage & Nil \\
\hline \multirow[t]{3}{*}{ Aloe vera mucilage } & JAV1 & $0.1 \%$ & 10 \\
\hline & JAV2 & $0.2 \%$ & 20 \\
\hline & JAV4 & $0.4 \%$ & 40 \\
\hline \multirow[t]{3}{*}{ Flax seed mucilage } & JFS1 & $0.1 \%$ & 10 \\
\hline & JFS2 & $0.2 \%$ & 20 \\
\hline & JFS4 & $0.4 \%$ & 40 \\
\hline \multirow[t]{3}{*}{ Fenugreek mucilage } & JFG1 & $0.1 \%$ & 10 \\
\hline & JFG2 & $0.2 \%$ & 20 \\
\hline & JFG4 & $0.4 \%$ & 40 \\
\hline \multirow[t]{3}{*}{ Purslane mucilage } & JPS1 & $0.1 \%$ & 10 \\
\hline & JPS2 & $0.2 \%$ & 20 \\
\hline & JPS4 & $0.4 \%$ & 40 \\
\hline \multirow[t]{3}{*}{ Malabar spinach mucilage } & JMS1 & $0.1 \%$ & 10 \\
\hline & JMS2 & $0.2 \%$ & 20 \\
\hline & JMS4 & $0.4 \%$ & 40 \\
\hline
\end{tabular}




\section{Preparation of jaggery using plant mucilage clarificants}

$10 \mathrm{~L}$ of Sugarcane raw juice was extracted and added with lime to adjust $\mathrm{pH}$ from 5.2 to 6.5 [24] and boiled. During boiling different concentrations $(0.1 \%, 0.2 \%$ and $0.4 \%)$ of plant mucilage clarificants were added in 2 or 3 lots in sequence. The scum formed was filtered through juice strainer and the residue was weighed and recorded. The processing of boiling was continued until the juice attains a temperature of $118^{\circ} \mathrm{C}$ to $120^{\circ} \mathrm{C}$. The hot syrup was allowed to cool and transferred into moulds of different shapes and sizes for solidification. The processing time for jaggery preparation and yield of jaggery was also recorded. The jaggery prepared was stored under dry conditions for further analysis.

\section{RESULTS AND DISCUSSION}

The mucilage extracted from selected plants sources was analysed by molisch's test and ruthenium red test to confirm the presence of mucilage components such as carbohydrates/polysaccharides and observations were reported in the table 4 . All the plant mucilage extracts were positive for both molisch's test and ruthenium red test, these results suggest that the extracted samples contain mucilage.

Table 4: Confirmative test for plants mucilage clarificants

\begin{tabular}{lll}
\hline Clarificants & Molisch's test & Ruthenium red test \\
\hline Control(Dist water) & - & - \\
Aloe vera Mucilage & + & + \\
Flax seeds Mucilage & + & + \\
Fenugreek Mucilage & + & + \\
Purslane Mucilage & + & + \\
Malabar Spinach mucilage & + & + \\
\hline
\end{tabular}

-ve indicants no reaction and+ve indicates Positive

The effect of plant mucilage clarificants on jaggery processing was assessed by amount of Scum (\%), total processing time (min) and Jaggery yield (\%). The observations were recorded in the table 5 .

Table 5: Effect of different plant mucilage clarificants on scum, processing time and yield of jaggery

\begin{tabular}{llll}
\hline Sample & Scum (\%) & Processing time (min) & Jaggery yield (\%) \\
\hline JNC & $1.82 \pm 0.11$ & $96.67 \pm 2.52$ & $8.14 \pm 0.22$ \\
JAV1 & $3.05 \pm 0.02$ & $80.67 \pm 2.08$ & $10.15 \pm 0.05$ \\
JFS1 & $2.43 \pm 0.04$ & $87.33 \pm 2.08$ & $9.72 \pm 0.13$ \\
JFG1 & $2.73 \pm 0.07$ & $83.67 \pm 2.08$ & $9.95 \pm 0.05$ \\
JPS1 & $2.26 \pm 0.05$ & $88.67 \pm 0.58$ & $9.50 \pm 0.11$ \\
JMS1 & $2.10 \pm 0.02$ & $90.67 \pm 3.06$ & $9.23 \pm 0.13$ \\
JAV2 & $3.50 \pm 0.10$ & $77.33 \pm 2.08$ & $10.62 \pm 0.05$ \\
JFS2 & $2.70 \pm 0.05$ & $85.33 \pm 1.15$ & $10.15 \pm 0.03$ \\
JFG2 & $2.92 \pm 0.10$ & $80.33 \pm 2.52$ & $10.28 \pm 0.04$ \\
JPS2 & $2.42 \pm 0.04$ & $86.00 \pm 1.73$ & $9.82 \pm 0.08$ \\
JMS2 & $2.23 \pm 0.06$ & $88.00 \pm 1.00$ & $9.57 \pm 0.12$ \\
JAV4 & $4.07 \pm 0.08$ & $72.33 \pm 1.53$ & $10.92 \pm 0.02$ \\
JFS4 & $3.15 \pm 0.05$ & $78.67 \pm 2.31$ & $10.30 \pm 0.03$ \\
JFG4 & $3.42 \pm 0.10$ & $75.33 \pm 1.53$ & $10.44 \pm 0.06$ \\
JPS4 & $2.86 \pm 0.09$ & $81.33 \pm 3.21$ & $10.18 \pm 0.03$ \\
JMS4 & $2.68 \pm 0.08$ & $83.33 \pm 0.58$ & $9.91 \pm 0.06$ \\
\hline
\end{tabular}

Values expressed as mean \pm SD $(n=3)$

The scum (\%) was recorded in the range of $2.1 \%$ to $4.07 \%$. against control (1.82\%). All the plant mucilage clarificants used in this study showed dose dependent improvement in removing the good quantity of scum over control (table 5). However, the mucilage clarificants of Aloe vera (JAV4) showed remarkable effect on formation of scum compared to other plant mucilage clarificants used in this study and control (table 5) and the same was presented in fig. 1A. The mucilage clarificants when added during boiling of juice, the albumins present in the mucilage coagulates and carries the colloidal and suspended impurities present in the juice to the surface as scum which are then removed [25]. The amount of scum removed during the clarification indicates the quality of the jaggery, higher the amount scum removed better will be the quality because of removal of maximum non-sugar impurities thereby improving the colour and keeping quality of jaggery [26]. The results indicated that the selected plants mucilage as clarificants removed maximum impurities compare to control. Hence found to be effective clarificants in jaggery production. The effect of plant mucilage on jaggery processing time was recorded in the table 5 . The processing time for jaggery preparation was significantly reduced with the increase in the concentration of clarificants when compare to control (96.67 $\mathrm{min}$ ). The processing time was observed between minimum of 72.33 min (JAV4) to maximum of 90.67 min (JMS1). All plant mucilage clarificants showed maximum reduction in processing time at $0.4 \%$ when compare to concentration of $0.1 \%$ and $0.2 \%$ respectively. The same was presented in the fig. $1 \mathrm{~B}$. Among all the clarificants used in the jaggery production JAV4 showed maximum reduction in processing time. Increase in the processing time may cause caramelization of various sugars and may effect colour of jaggery [27]. Also reduction in the processing time can reduce the amount of fuels to be used for processing thus indirectly contributing to cost reduction and also losses of nutrients contents will be minimal due to lesser processing time. It was also found (table 5) that the application of plants mucilage improves the yield of the jaggery on dosage depended pattern i.e., increase in the concentration of mucilage, the yield of the jaggery was improved (table 5). The highest yield was recorded in JAV4 (10.92\%) and lowest yield was observed in JMS1 (9.23). The jaggery yield in control JNC was $8.14 \%$. It was observed that the application of Aloe vera plant mucilage clarificants (JAV4) in jaggery production effectively improved the jaggery yield (fig. 1C) when compare to other clarificants and control. Similar results were found by using $H$. vitifolius as clarificant in jaggery manufacture unit Mandya district of Karnataka [28], it has shown remarkable settling characteristics; the 
settling was faster and the mud was more or less equal to that with chemical flocculants [29]. Also the trend of increase in herbal clarificants concentration influencing the yield and processing time was reported [30]. The current research was in line with the recommendation made by using bhendi powder for clarification of sugarcane juice for removal of maximum scum, improving the colour and jaggery yield [1]. Thus the selected plants mucilages are found to be efficient clarificants and can be used in the jaggery production.
A

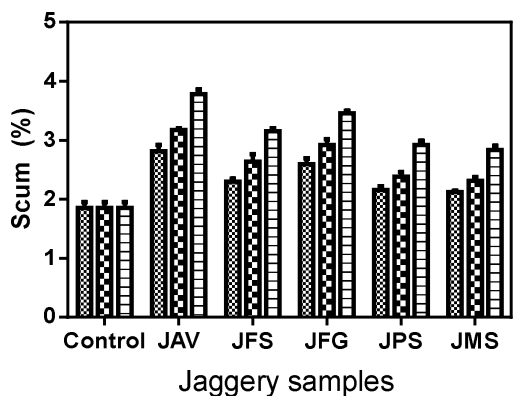

B

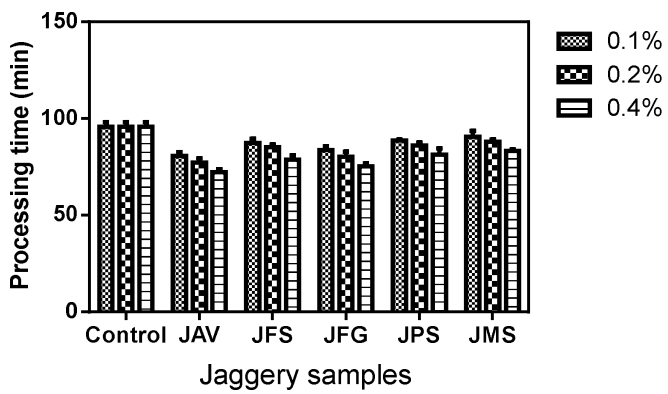

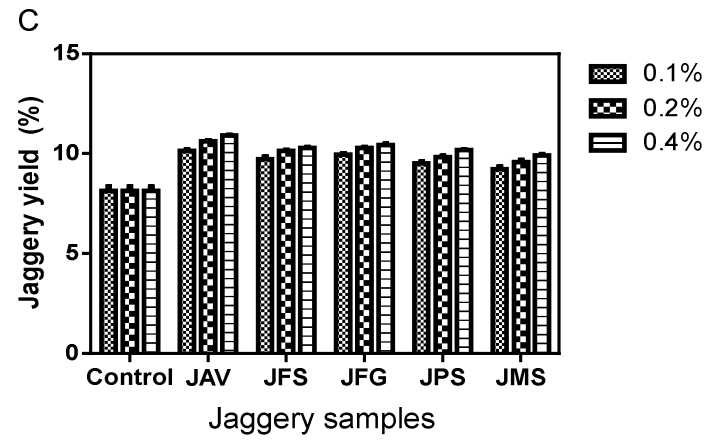

Fig. 1: Effect of plant mucilage clarificants on (A) Scum in percent of the weight, (B) Processing time and (C) Jaggery Yield in percentage of weight. All the values presented as mean \pm standard deviation $(n=3)$

\section{CONCLUSION}

The selected plants mucilage used as clarificants in the jaggery production found to be effective in removing maximum scum reduce processing time and improve the yield of jaggery. It was found that the processing efficacy was increased with the increase in the concentration of plant mucilage clarificants. Thus the selected plant mucilage can be used as alternative sources to chemical clarificants. The natural plant based materials are considered to be advantageous compared to chemical clarificants because of their natural origin, ecofriendlyness, local availability so that plant materials can be collected in large quantities and simple method of extraction of mucilage. The production cost is also much lower compared with that of synthetic clarificants.

Therefore the application of plants mucilage as clarificants in jaggery production can get the market potential to meet the domestic and international requirements. There by the decentralised jaggery industries could stabilise and improve the livelihood of farmers and manufactures especially in rural areas.

\section{ACKNOWLEDGMENT}

The authors are thankful to Mr. Praveen kumar (Kaveri foods, Tubinakere Industrial area, Mandya district) for assisting in trails and production of Jaggery.

\section{CONFLICT OF INTERESTS}

We declare that there is no conflict of interest

\section{REFERENCES}

1. Patil JE, Shinde US, Nevkar GS, Singh J. Clarification efficiency of synthetic and herbal clarificants in quality jaggery production. Sugar Tech 2005;7:77-81.
2. Kumar V, Vijay VK, Agarwal US. Studies on centrifugal clarification of sugarcane juice-possibilities and limitations. Agric Eng Int: CIGRE J 2008;10:6-29.

3. Usha R, Neena J, Shivaramu HS, Sheela K, Sunanda S. Processing practices of jaggery manufacturers in cauvery command Area of Karnataka, Co-operative Sugar 2004;35:853-6.

4. Shankunthala VA. Proceeding of National seminar on jaggery manufacture and storage; 1985. p. 90-3.

5. Baboo B. PSO-SVM applied to SWASV studies for accurate detection of $\mathrm{Cd}(\mathrm{II})$ based on disposable electrode. J Agric Eng 1991; Suppl:252-63.

6. Baboo B, Solomon B. Nutritive sweeteners from sugar crops: development of Jaggery, Khandsari and Syrup Industries in India. Sugarcane Agro-industrial alternatives. Singh G and Solomon (Eds); 1995. p. 289-12.

7. Nagalakshmi AVD, Uma RM. Quality analysis of selected fruit juices sold by street vendors in hyderabad city. Indian J Nutr Dietet 1999;36:78.

8. Anonymous. Bureau of Indian Standards, IS 12923, (Clause 4.3 and 6.1), New Delhi; 1990.

9. Nayaka H, Sathisha UV, Manohar MP, Chandrashekar KB, Dharmesh SM. Cytoprotective and antioxidant activity studies of jaggery sugar. Food Chem 2009;115:113-8.

10. Rangari VD. Pharmacognosy and phytochemistry. $1^{\text {st }}$ edn. Carrier publication, Nashik; 2002.

11. Hamman JH. Composition and application of Aloe vera leaf gel. Molecules 2008;13:1599-16.

12. Verma PRP, Balkishen R. Studies on Leucaena leucocephala seed gum: emulsifying properties. J Sci Indian Res 2003;62:198-6.

13. Mahadevarao US, Zin T. In vivo study on diuretic and laxative therapeutic properties of hydro-alcoholic extract of lu hui (Lilliaceae) on experimental rodents (Rattus norvegicus). Asian J Pharm Clin Res 2014;7:147-51.

14. Wenzel GE, Fontana JD, Correa JBC. Applied Biochemistry and Biotechnology; 1990;24:341. 
15. Shankunthala VA. Proceeding of National seminar on jaggery manufacture and storage; 1985. p. 90-3.

16. Singh H, Gill PS. Comparitive efficiency of certain organic clarificants in gur manufacture. Second Biannual Conf. Sug Res and Dev Workers; 1954. P. 613-5.

17. Laxmikantham. Importance of jaggery in Andhra Pradesh. Technology in Sugarcane growing, Andhra Pradesh Agricultural University, Hyderabad (India); 1973. p. 60-70.

18. Jayamala GB, Chowde Gowda M, Ramya HN, Shankar M, Krishnamma PN. Prospects of jaggery industry in karnataka-a case study. Int J Appl Agric Res 2009;4:203-14.

19. Shafi N, Khan L, Khan GA. Commercial extraction of gel from Aloe vera (L) leaves. J Chem Soc Pak 2000;22:47-9.

20. Inamdar $M$, Abhang $P$, Momin $M$. Isolation and evaluation of fenugreek, flaxseed mucilages and its use as a pharmaceutical binder. Int J Pharm Technol 2012;4:4766-77.

21. Chattoraj S, Bandyopadhyay AK. Development and evaluation of Donut matrix tablets of bracofen using mucilaginous polymer from Portulaca oleracea Linn. Pharm Ind 2010;72:11.

22. Hameed AM, Ramzy S Hamied, Zainab Y Shnain. Drag-reducing agent for aqueous liquid flowing in turbulent mode through pipelines. Al-Khwarizmi Eng J 2014;10:15-22.

23. Kulkarni GT, Gowthamarajan K, Brahmajirao G, Suresh B. Evaluation of binding properties of selected natural mucilages. J Sci Ind Res 2002;61:529-32.
24. Shahi HW. National seminar on status and prospects of jaggery and khandsari industries in India; 1999. p. 20-6.

25. Chavan UD. Final report of AD-HOC research project on preparation of mucilage from okra cortex. Department of Biochemistry, Mahatma Phule Krishi Vidyapeeth, Rahuri; 2002.

26. Ragavan T, Thirumurugan A, Sathiya K, Sundra Vadana S. A case study: studies on quality jaggery (gur) production with organic clarificants. Int $\mathrm{J}$ Forestry Crop Improvement 2011;2:207-10.

27. Buera P, Chirife J, Resnik SL, Lozano RD. Non enzymatic browing in liquid model system of high water activity: Kinetics of colour change due to caramelization of various single sugars. J Food Sci 1987;52:1059-62.

28. Thangamuthu P. A vegetable clarifying agent for cane juice clarification. Cooperative Sugar 2009;40:49-51.

29. Chauhan AK, Sharma S, Sharma P, Maheshwari R. Production of organic sugar employing vegetable clarifying agent for sugarcane juice. Int J Institutional Pharm Life Sci 2012;2:312-5.

30. Mungare TS, Jadhav HD, Shinde US, Jadhav BS, Singh J. Clarification technique in quality jaggery making-a review. Cooperative Sugar 2005;32:1013-7. 